\title{
LAS ÁREAS MARINAS PROTEGIDAS: NUEVAS PERSPECTIVAS A LA LUZ DE LA LEY 42/2007, DEL PATRIMONIO NATURAL Y DE LA BIODIVERSIDAD
}

\author{
MARÍA GimÉnez CASALDUERO \\ Profesora ayudante \\ Departamento de Derecho Administrativo. Universidad de Murcia \\ mariagim@um.es
}

Recibido: 8 de abril de 2010 / Aceptado: 20 de Mayo de 2010

RESUMEN: El presente trabajo se ocupa de analizar la protección del medio marino a través de la recién incorporada figura de Área Marina Protegida al ordenamiento jurídico ambiental español, prestando especial atención a la delimitación de competencias entre el Estado y las Comunidades Autónomas en relación a la biodiversidad marina en aplicación de la Ley 42/2007, de Patrimonio Natural y de la Biodiversidad. Se aborda asimismo, el estudio de la Red de Áreas Marinas Protegidas, regulada en el hoy Proyecto de Ley de Protección del Medio Marino, fruto de la transposición de la Directiva sobre la Estrategia Marina y sus implicaciones en relación a las categorías de espacios naturales protegidos que integra.

RESUM: Aquest treball s'ocupa d'analitzar la protecció del medi marí a través de la figura incorporada recentment d'àrea marina protegida a l'ordenament jurídic ambiental espanyol, tot prestant una atenció especial a la delimitació de competències entre l'Estat i les comunitats autònomes en relació amb la biodiversitat marina en aplicació de la Llei 42/2007, de patrimoni natural i de la biodiversitat. S'hi tracta, així mateix, l'estudi de la Xarxa d'Àrees Marines Protegides, regulada en el que encara avui és el Projecte de llei de protecció del medi marí, fruit de la transposició de la Directiva sobre l'estratègia marina i les seves implicacions amb relació a les categories d'espais naturals protegits que integra.

ABSTRACT: This study analyzes the protection of marine environment through the newly incorporated institution, the Protected Marine Area, in the Spanish environmental Law, giving 
particular attention to the distribution of powers between State and the Autonomous Communities regarding to marine biodiversity, in application of the Natural Heritage and Biodiversity Act 2007. Moreover, it is studied the Protected Marine Area Network, which has to be regulated in the future Marine Environment Protection Act, now still a draft. This new regulation has to be the transposition of the Marine Strategy Directive, taking into account the implications regarding to the categories of protected natural areas which integrates.

PALABRAS ClAVE: Áreas Marinas Protegidas - Ley de Patrimonio Natural y de la Biodiversidad - protección de biodiversidad marina

PARAULES CLAU: Àrees marines protegides - Llei de patrimoni natural i de la biodiversitat — protecció de biodiversitat marina

KEYWORDS: Protected Marine Areas — Natural Heritage and Biodiversity Act — marine biodiversity protection

Sumario: I. La protección de áreas marinas: una intervención pública necesaria marcada por su retraso. II. Cuestiones introductorias en torno a la nueva figura de protección en el medio marino español: las áreas marinas protegidas. 1 ¿Qué es un área marina protegida? 2. Tipos de áreas marinas protegidas previstas en la Ley 42/2007, del Patrimonio Natural y de la Biodiversidad. 3. Especial referencia a las Reservas Marinas de interés pesquero. III. Distribución de competencias en el medio marino a la luz de la Ley 42/2007, del patrimonio natural y de la biodiversidad. IV. La futura red de áreas marinas protegidas de España. V. Valoración final sobre las competencias autonómicas en el medio marino. VI. Bibliografía.

\section{LA PROTECCIÓN DE ÁREAS MARINAS: UNA INTERVENCIÓN PÚBLICA NECESARIA MARCADA POR SU RETRASO}

La primera Área Marina Protegida a nivel mundial fue el Santuario Marino de Fort Jeferson (Florida, 1932), y se declaró sesenta años después del primer Parque Nacional más antiguo del mundo de ámbito terrestre, el Parque Nacional de Yellowstone, 1872. En la cuenca mediterránea, sería el Parque Nacional de Port-Cros (Francia) el considerado como la primera zona protegida que incluyó área marina, siendo declarado en 1963. Este retraso temporal en el establecimiento de medidas de protección hacia áreas marinas es ilustrativo del desinterés de los Estados en la protección del medio marino, etiquetado hasta épocas recientes como fuente 
de recursos ilimitados, calificación ésta que ha quedado superada gracias al avance en conocimientos científicos sobre este medio que han demostrado la necesidad de preservar los ambientes marinos y sus recursos ante múltiples amenazas. Por otra parte, la desprotección se ve reflejada en términos de superficie, en los datos que nos demuestran que solo un $0,5 \%$ de los mares está protegido, y en el caso mediterráneo, las Áreas Marinas Protegidas (en adelante AMPs) representan sólo un $1 \%$ de su superficie, en comparación con casi el $15 \%$ de la superficie terrestre bajo alguna figura de protección ${ }^{1}$.

En España, la primera AMP exclusivamente marina está actualmente en proceso de declaración a través de la Orden ARM/3840/2008, de 23 de diciembre, por la que se aprueban medidas para la protección de la zona marina de El Cachucho ${ }^{2}$, fruto de la aplicación de la Ley 42/2007, de 13 de diciembre, de Patrimonio Natural y Biodiversidad (en adelante LPNB) que incluye la figura de AMP y deroga la Ley 4/1989, de 27 de marzo, de Conservación de los Espacios Naturales y de la Flora y Fauna Silvestres. Según reza la Exposición de Motivos de la LPNB, la Ley 4/89 introdujo en España desde una perspectiva integral el Derecho de conservación de la naturaleza internacionalmente homologable propiciando grandes logros en materia de protección de la naturaleza, pero enfocados estos especialmente al medio terrestre. Sin embargo, y a pesar de hacer referencia en alguno de sus preceptos al medio marino (art. 10.1, definición de espacio natural protegido), la derogada Ley no prestó prácticamente atención a la protección de la biodiversidad marina, motivo por el cual una reforma en este sentido resultaba imprescindible.

Haciendo un balance de los antecedentes normativos de ámbito internacional relacionados con la creación de AMPs, es preciso destacar el Convenio de Barcelona de 1976, denominado "Convenio para la Protección del Medio Marino y de la Región Costera del Mediterráneo" tras las enmiendas de 1995. Este Convenio ya promovió el establecimiento de AMPs, aunque circunscritas al ámbito Mediterráneo, gracias al Protocolo sobre las Zonas Especialmente Protegidas y la Diversidad Biológica en el Mediterráneo de 1995, y que fue ratificado por España en fecha posterior a la elaboración de la Ley $4 / 1989^{3}$. Pero los recientes avances en el

\footnotetext{
${ }^{1}$ WWF (2005, septiembre), Conservando nuestros paraisos marinos. Propuesta de Red Representativa de Áreas Marinas Protegidas de España. Recuperado el 6 de abril de 2010, de http://assets.wwfes.panda.org/downloads/conservando_nuestros_paraisos_marinos_peninsula_iberica_y_bale ares1.pdf

${ }^{2}$ BOE núm. 2, de 2.01.2009.

${ }^{3}$ Instrumento de Ratificación del Protocolo sobre las zonas especialmente protegidas y la diversidad biológica en el Mediterráneo y anexos, adoptado en Barcelona el 10 de junio de 1995 y en Montecarlo el 24 de noviembre de 1996, respectivamente. (BOE, núm 302, de 18 de diciembre de1999).
} 
ámbito del Derecho comunitario han sido sin duda los que han generado el impulso necesario para que el ordenamiento jurídico español salde la deuda con el medio marino. En este sentido, el Sexto Programa de Acción de Medio Ambiente (Sexto PMA, 2002) ya incluyó dentro de sus Estrategias Temáticas una específicamente orientada a la protección del medio marino con el objetivo de promover la utilización sostenible de los mares y proteger los ecosistemas marinos (Hacia una estrategia de protección y conservación del medio ambiente marino, $\operatorname{COM(2002)~} 539$ final).

Más recientemente, en el año 2008, se adopta la Directiva 2008/56/CE del Parlamento Europeo y del Consejo, de 17 de junio, por la que se establece un marco de acción comunitaria para la política del medio marino (Directiva Marco sobre la Estrategia Marina, en adelante DMEM) con el objetivo de establecer un marco para que los Estados miembros adopten sus propias estrategias encaminadas a conseguir un buen estado ecológico de las aguas marinas de las que sean responsables para el 2021.

La DMEM establece que en cada región o subregión marina los Estados miembros deberán elaborar sus Estrategias marinas (España tiene jurisdicción tanto en la región Atlántica como en la Mediterránea), sobre las cuales se determinarán las medidas necesarias para lograr o mantener un buen estado medioambiental. Los programas de medidas establecidos en el artículo 13.4 de la Directiva “incluirán medidas de protección espacial que contribuyan a la constitución de redes coherentes y representativas de zonas marinas protegidas que cubran adecuadamente la diversidad de los ecosistemas que las componen, como son las zonas especiales de conservación con arreglo a la Directiva sobre hábitats, las zonas de protección especial con arreglo a la Directiva sobre aves, y las zonas marinas protegidas acordadas por la Comunidad o los Estados miembros interesados en el marco de los acuerdos internacionales o regionales de que sean Partes".

La DMEM entró en vigor el 15 de julio de 2008 y tiene como fecha límite de incorporación al Derecho interno de cada Estado el 15 de julio de 2010. En este sentido España ya ha comenzado su transposición a través del Proyecto de Ley de Protección del Medio Marino (versión de 12 de marzo de 2010), texto que además regula otros aspectos de la protección del medio marino que hasta ahora no habían sido abordados en la legislación estatal, en concreto 
lo referente a la Red de Áreas Marinas Protegidas de España y la conservación de especies marinas ${ }^{4}$.

La creación de zonas protegidas marinas no solamente contribuye a conseguir el buen estado medioambiental del medio marino que persigue la DMEM, sino que permitirá cumplir los compromisos adquiridos en la Cumbre Mundial sobre Desarrollo Sostenible (Johannesburgo, 2002) y en el Convenio sobre la Diversidad Biológica (CDB), de crear una red global de AMPs para el 2012, tanto en aguas jurisdiccionales como en alta mar. Recordemos que fueron las Decisiones VII/5 y VII/28 de la Conferencia de las Partes del CDB (Kuala Lumpur, 2004) las que han dejado clara la potestad de los Estados ribereños de establecer AMPs en su mar territorial y Zona Económica Exclusiva.

La LPNB destaca en su Exposición de Motivos la importancia de incorporar al régimen de protección de los espacios naturales la categoría de Áreas Marinas Protegidas, y la creación de la red de áreas marinas protegidas, en línea con las directrices de la Unión Europea. En este sentido, el presente trabajo tratará de analizar el régimen jurídico de esta figura y su repercusión en el sistema de espacios naturales protegidos marinos en España.

\section{CUESTIONES INTRODUCTORIAS EN TORNO A LA NUEVA FIGURA DE PROTECCIÓN EN EL MEDIO MARINO ESPAÑOL: LAS ÁREAS MARINAS PROTEGIDAS}

A lo largo de la historia de la conservación in situ de la biodiversidad marina, las reclamaciones para crear figuras ad hoc para los espacios marinos han sido constantes. En España la LPNB, Ley 42/2007, de 13 de diciembre, introduce una nueva categoría de espacio natural protegido pensada exclusivamente para proteger el medio marino, las Áreas Marinas Protegidas (AMPs).

A pesar de su novedad en el ordenamiento jurídico español, las AMPs son una figura sobradamente conocida a nivel internacional, y especialmente bien estudiada desde el ámbito científico. Su incorporación al régimen jurídico básico de la conservación, uso sostenible, mejora y restauración del patrimonio natural y de la biodiversidad permite otorgar el merecido protagonismo que se reclamaba para los espacios marinos en el seno de la

\footnotetext{
${ }^{4}$ A la fecha de cierre de éste trabajo el Proyecto de Ley de Protección del Medio Marino se encuentra en el Congreso sujeto a un plazo de ampliación de enmiendas hasta el día 6 de abril de 2010, para culminar así el proceso destinado a su aprobación definitiva antes de julio de 2010.
} 
legislación ambiental, aún así, la fórmula elegida para este fin ha sido objeto de críticas, "la figura de área marina protegida resulta poco definida, no tanto porque el artículo que la introduce no sea claro sino porque lo más normal es que en el mundo real no se trate de una categoría específica de espacio natural protegido sino una categoría genérica para agrupar, por la especialidad que supone el medio marino, otras categorías cuando se establecen en el mar" (...) "parece confuso crear una categoría que lo más normal es que sea otra cosa acogida a otra categoría"

\section{1. ¿Qué es un área marina protegida?}

En sentido estricto se puede afirmar que un AMP es una técnica de gestión in situ de la biodiversidad del medio marino. Sin embargo, bajo la denominación de AMP o cualquiera de las denominaciones tradicionales (Santuario, Parque Marino, Área Protegida, etc.,) podemos encontrarnos con una regulación sectorial de determinado uso como por ejemplo la limitación de la caza de una especie (ballenas), o con el objetivo de proteger a las poblaciones de determinada especie (tortugas marinas).

Una definición de área marina protegida comúnmente aceptada desde el ámbito científico y adoptada por la Unión Internacional de Conservación de la Naturaleza (UICN) sería: "cualquier área intermareal o submareal terrestre, junto con el agua circundante, su flora y fauna asociada y sus características culturales, los cuales han sido preservadas por ley u otro medio efectivo de protección de una parte o todo un medio ambiente"6. Otra definición más reciente de AMP la encontramos gracias al trabajo del grupo Especial de Expertos Técnicos (GEET) sobre áreas protegidas marinas y costeras ${ }^{7}$ : "Área protegida marina y costera' significa toda zona definida dentro del medio marino o contigua al mismo, junto con las aguas que la cubren y la flora, fauna y rasgos históricos y culturales asociados, que ha sido reservada por acto legislativo o por otros medios efectivos, incluso la costumbre, para que su diversidad biológica marina y/o costera goce de un nivel de protección superior al de su entorno.

\footnotetext{
${ }^{5}$ Consejo de Estado, Dictamen 913/2007, de 17/5/2007.

${ }^{6}$ UICN, Directrices para las categorías de Manejo de Áreas protegidas, Centro de Parques Nacionales y Áreas Protegidas (CPNAP) - Centro Mundial de Monitoreo de la Conservación (WCMC), Cambridge. 1995.

${ }^{7}$ Definición adoptada en la séptima Conferencia de las Partes (CdP) del Convenio de Diversidad Biológica, (Kuala Lumpur, febrero 2004), en la Decisión VII/5 párrafo 10, la cual incorpora todas las categorías de áreas protegidas de la UICN.
} 
Las áreas dentro del medio marino incluyen aguas de mar poco profundas permanentes, bahías, estrechos, lagunas; estuarios; lechos acuáticos submareales (lechos de algas marinas, lechos de costera marítima, praderas marinas tropicales), arrecifes de coral, limos intermareales, marismas y pantanos de arena o de sal; cabezos submarinos, corales de aguas profundas, fuentes de aguas profundas y hábitats oceánicos" ${ }^{\prime 8}$.

Sin embargo, si buscamos una definición expresa de AMPs en nuestro ordenamiento jurídico, comprobamos su inexistencia hasta la LPNB, ya que la Ley 4/89 establecía solamente categorías de Espacios Naturales Protegidos (ENPs) pensadas para el medio terrestre, aunque eran aplicables a ámbitos costeros o marítimos-terrestres, con los consabidos problemas competenciales que se plantearon desde la STC 195/1998, sobre la Ley 6/1992, de declaración de la Reserva natural de las Marismas de Santoña y Noja. Por tanto, hasta la LPNB se hacia equivaler AMP a espacio natural protegido, situado en el mar.

Según la LPNB, un espacio natural protegido esta definido en el artículo 27 como, "aquellos espacios del territorio nacional, incluidas las aguas continentales, y las aguas marítimas bajo soberanía o jurisdicción nacional, incluidas la zona económica exclusiva y la plataforma continental, que cumplan al menos uno de los requisitos siguientes y sean declarados como tales: a) contener sistemas o elementos naturales representativos, singulares, frágiles, amenazados o de especial interés ecológico, científico, paisajístico, geológico o educativo. b) Estar dedicados a especialmente a la protección y el mantenimiento de la diversidad biológica, de la geodiversidad y de los recursos naturales y culturales asociados".

Esta definición incluye las aguas marítimas en el concepto de ENP, diferenciando así el territorio nacional del medio marino. La consideración de que el mar no es territorio (avalada por la STS, de 20 septiembre 1984, y por la STC 38/2002) nos permite determinar que el territorio de una CCAA llegará hasta la zona marítimo-terrestre, siendo su proyección más allá de éstas aguas una excepción (en este sentido, son determinantes las regulaciones contenidas en los distintos Estatutos de Autonomía a la hora de definir su territorio), interpretación ésta seguida, como veremos, por la LPNB. Asimismo, se manifiesta la Ley 22/1988, de 28 de julio, de Costas modificada por la Ley 53/2002, de 30 de diciembre, de medidas fiscales, administrativas y del orden social, que incorporó el siguiente párrafo al artículo 114, "la competencia autonómica sobre ordenación territorial y del litoral, a la que se

\footnotetext{
${ }^{8}$ Definición extraída de BARREIRA, A., et al., Gobernanza para la protección del medio marino en España: Guía Práctica, Madrid, Instituto Internacional de Derecho y Medio Ambiente (IIDMA), 2009.
} 
refiere el párrafo anterior, alcanzará exclusivamente al ámbito terrestre del dominio público marítimo-terrestre, sin comprender el mar territorial y las aguas interiores".

Por tanto, será el artículo 32 de la LPNB el que introduzca por primera vez en España, con carácter básico, una figura de protección desde el punto de vista de la conservación, pensada expresamente para el medio marino, y la define como: "las áreas marinas protegidas son espacios naturales designados para la protección de ecosistemas, comunidades o elementos biológicos o geológicos del medio marino, incluidas las áreas intermareal y submareal, que en razón de su rareza, fragilidad, importancia o singularidad, merecen una protección especial. Podrán adoptar esta categoría específica o protegerse mediante cualquier otra figura de protección de áreas prevista en esta Ley, en cuyo caso, su régimen jurídico será el aplicable a estas otras figuras, sin perjuicio de su inclusión en la Red de Áreas Marinas Protegidas" (art. 32.2).

Según el nuevo régimen de la legislación básica del Estado, las AMPs serían una más de las categorías de espacios naturales protegidos del artículo 29 LPNB. A su vez, los espacios naturales marinos clasificados conforme a alguna de las categorías jurídicas de espacios naturales protegidos de las previstas en la Ley (Parques, Reservas, Monumentos y Paisajes Protegidos, ZEC, ZEPIM, Reserva de la Biosfera, Áreas OSPAR, etc.), podrán ser AMPs, pero adoptarán el régimen jurídico previsto para cada una de ellas. Por tanto las AMPs, se configuran como una categoría individualmente considerada y a su vez como un género común, y tal y como considera Mercedes ORTÍZ GARCÍA ${ }^{9}$, sería un concepto que abarcaría al resto de categorías siempre que su ámbito espacial se oriente al medio marino.

En conclusión, a tenor del texto de la Ley, ¿cuándo estamos ante un AMP?. Si se trata de un espacio marino de los delimitados en el artículo 32 siempre serán AMPs los ENP, cuándo su objeto sea la protección de un espacio marino, ya sea mixto (marítimo-terrestre) o exclusivamente marino. Esta afirmación se ve reforzada por el literal del párrafo 2 del artículo 27 de la LPNB, en el que diferencia los ámbitos que pueden encuadrarse en la figura de ENP, pudiendo abarcar en su perímetro ámbitos terrestres exclusivamente, simultáneamente terrestres y marinos o exclusivamente marinos. Siguiendo con la teoría de la autora ${ }^{10}$, tal vez habría sido más adecuado, a pesar de la idoneidad de AMP, distinguir entre parques

\footnotetext{
9 ORTÍZ GARCÍA, M., La gestión eficiente de la zona costera. Los Parques marinos. Tirant lo blanch, Valencia, 2003, p. 81.

${ }^{10}$ ORTÍZ GARCÍA, M., La conservación de la biodiversidad marina: las áreas marinas protegidas. Comares, Granada, 2002, p. 165ss.
} 
marítimos-terrestres, si comprende espacio terrestre y parques marinos si prevalece el elemento marino y su cercanía a la costa, reservando el de santuario marino para zonas alejadas $^{11}$.

Hasta la propuesta de declaración de El Cachucho como AMP exclusivamente marina, situada en aguas de la ZEE española y gestionada por el Estado, todas las AMPs declaradas en España habían sido mixtas y gestionadas por las CCAA (en 1978 se declaró la primera AMP de España, el Parque Natural de Cabo de Gata-Nijar).

\section{Tipos de áreas marinas protegidas previstas en la Ley 42/2007 de Patrimonio Natural} y de la Biodiversidad

De la definición de AMP de la Ley 42/2007, artículo 32.1, se desprende que el medio marino podrá protegerse mediante ésta categoría específica o por cualquier otra figura de protección prevista en la Ley, en cuyo caso su régimen jurídico será el previsto para cada una de ellas.

Junto a las categorías nacionales previstas en el artículo 29 (parques, reservas naturales, monumentos naturales y paisajes protegidos), estarían las autonómicas que suelen asimilarse a las estatales previstas en legislación básica, pero esto no ha impedido que en función de su competencia para establecer normas adicionales de protección, las CCAA establezcan categorías diferentes. En cualquier caso, y siguiendo los parámetros del artículo 36.1 de la LPNB, las CCAA pueden declarar ENP (en función de las categorías recogidas en la legislación autonómica) en su ámbito territorial y en las aguas marinas, en caso de que exista continuidad ecológica entre el espacio natural terrestre objeto de protección y el ecosistema marino.

Además de las categorías nacionales y autonómicas, la LPNB recoge un amplio elenco de categorías internacionales previstas en los Convenios y Acuerdos internacionales validamente celebrados por España, y que como apunta el artículo 96 de la CE, pasan a formar parte del Derecho interno, creando obligaciones de cumplimiento. En este sentido hay muchos instrumentos internacionales que obligan a España y la mayoría de ellos contiene referencias expresas a las AMPs. En particular, el artículo 40 de la LPNB hace referencia a los siguientes:

\footnotetext{
${ }^{11}$ Esta postura fue defendida por el Consejo de Estado en su Informe sobre la Protección de Hábitats y Especies marinas, elaborado a petición del Gobierno y aprobado el 9 de julio de 2006, en el que aconsejaba la creación de una o dos nuevas figuras de espacio natural protegido, el Área Marina Protegida y el Área Marítimo-Terrestre Protegida, sobreentendiéndose que la primera abarcaría exclusivamente área marina. Dicho Informe se puede consultar en: http://www.consejo-estado.es/bases.html.
} 
a) Los humedales de importancia internacional, surgidos del Convenio relativo a los Humedales de Importancia Internacional especialmente como Hábitat de Aves Acuáticas (Ramsar, 1971). A pesar de no referirse expresamente a las AMPs, el 48\% de los sitios designados como zonas Ramsar, incluye ambientes costeros y marinos ${ }^{12}$. España tienen numerosos lugares Ramsar en su territorio, pero también en las zonas costeras y marinas adyacentes, por lo que en virtud del actual régimen de distribución de competencias de la LPNB serán estos humedales Ramsar siempre gestionados por las CCAA $^{13}$; b) Los sitios naturales de la Lista del Patrimonio Mundial, de la Convención sobre la Protección del Patrimonio Mundial, Cultural y Natural adoptado por la UNESCO (Paris, 1972) ${ }^{14}$; c) Las áreas protegidas, del Convenio para la Protección del Medio Ambiente Marino del Atlántico del Nordeste (OSPAR), Paris, 1998. En la reunión ministerial de la Comisión OSPAR (Sintra, 1998), se adopta el Anexo V que entra en vigor para España en el año 2000, y se centra en la protección y conservación de los ecosistemas y de la diversidad biológica de la zona marítima del Atlántico Nordeste. La Recomendación 2003/3 (Reunión Ministerial de Bremen, 2003) versa sobre la necesidad de establecer una Red OSPAR de AMPs, que en la actualidad asciende a $106^{15}$; d) Las Zonas Especialmente Protegidas de Importancia para el Mediterráneo (ZEPIM), del Convenio de Barcelona. En el Protocolo sobre las Zonas Especialmente Protegidas y la Diversidad Biológica en el Mediterráneo de 1995 se contempla la categoría internacional de Zonas Especialmente Protegidas de Importancia para el Mediterráneo (ZEPIMs), y las Zonas Especialmente Protegidas (ZEPs). El ámbito geográfico de ambas es la zona de mar mediterráneo, incluyendo el fondo del mar y su subsuelo, y se extiende, en el caso de los cursos de agua, hasta el límite del agua dulce, así como a las zonas costeras terrestres, incluidas las zonas húmedas que considere cada país (art.2) ${ }^{16}$; e) Los Geoparques,

\footnotetext{
${ }^{12}$ KELLEHER, G., Guidelines for Marine Protected Areas, IUCN, Gland - Cambridge. 1999.

${ }^{13}$ Como ejemplo de Humedales Ramsar en España estarían las Marismas de Santoña y Noja, Salinas de IbizaFormentera, así como los Parques Nacionales con humedales costeros como Doñana.

${ }^{14}$ Entre los bienes inscritos en la lista del patrimonio mundial, España cuenta con un espacio costero (Doñana) y uno marítimo (Ibiza, "Biodiversidad y Cultura"), declarado a la vez Patrimonio Cultural de la Humanidad -la Ciudadela- y Patrimonio Natural -las salinas y las praderas de posidonia.

${ }^{15}$ España ha incorporado a la red el Parque Nacional de las Islas Atlánticas de Galicia (2007), y ha propuesto recientemente El Cachucho.

${ }^{16}$ Las Zonas Especialmente Protegidas (ZEPs) podrán establecerse en las zonas marinas y costeras sometidas a la soberanía o jurisdicción de los países firmantes del Protocolo. Se prevé la elaboración y adopción de un plan de ordenación en el que se especifique el marco jurídico e institucional, así como la adopción de las medidas de ordenación y protección aplicables. La otra figura surgida del Protocolo es la referente a las Zonas Especialmente Protegidas de Importancia para el Mediterráneo (ZEPIM), espacios seleccionados por desempeñar una labor importante en la conservación de los componentes de la diversidad biológica que alberguen ecosistemas representativos de la zona mediterránea o hábitats de especies en peligro o que tengan un interés especial en el campo científico, estético, cultural o educativo (art. 8.2). Para las zonas situadas en alta mar
} 
declarados por la UNESCO ${ }^{17}$; f) Las Reservas de la Biosfera, declaradas por la UNESCO. La Ley 42/2007, introduce la Red española de Reservas de la Biosfera (arts. 65-67) como un subconjunto definido y reconocible de la Red Mundial de Reservas de la Biosfera, cuyos objetivos se determinan en el artículo 66 de la LPNB. ${ }^{18}$ Las Reservas de la Biosfera son “zonas de ecosistemas terrestres o costeros/marinos, o una combinación de los mismos, reconocidas en el plano internacional en el marco del Programa sobre el Hombre y la Biosfera (MaB) de la UNESCO"19. En la Conferencia Internacional sobre Reservas de la Biosfera (Sevilla, 1995) se estableció como una de las directrices a llevar a cabo, la de aplicar el concepto de reservas de la biosfera a los medios marino y costero, más que en el medio

total o parcialmente o en lugares en que los límites de la soberanía o jurisdicción nacionales no ha sido definidos aún, las Partes vecinas implicadas en la propuesta de inclusión proporcionarán el régimen jurídico, el plan de ordenación, las medidas aplicables y otros elementos previstos en el art. 9.3. Se exige que las zonas protegidas cuenten con un órgano de gestión y con un plan de ordenación cuyas reglas deberán estar definidas en el momento de inclusión de la zona en la lista y se aplicarán de inmediato. Finalmente se exige que la zona cuente con un programa de vigilancia continua. En España se ha aprobado la declaración de las siguientes ZEPIM: Paraje Natural Acantilados de Maro-Cerro Gordo, Isla de Alborán, Fondos Marinos del Levante de Almería, Parque Natural de Cabo de Gata-Nijar en Andalucía; Mar Menor y Zona Oriental Mediterránea de la Costa de Murcia; Parque Nacional Archipiélago de Cabrera en Baleares; Islas Columbretes en la Comunidad Valenciana, Parque natural de Cabo de Creus, e Islas Medes en Cataluña. Las Islas Chafarinas fueron rechazadas por la Conferencia de las Partes contratantes, pues según los datos de biodiversidad de la zona, la ZEPIM debía ser mucho más amplia y abarcar todo el mar de Alborán a propuesta conjunta con Marruecos. Para facilitar la aplicación del Protocolo sobre ZEPM del Convenio Barcelona se elabora el Plan de Acción Estratégico para la conservación de la biodiversidad marina y costera del mediterráneo. (SAP/BIO).

${ }^{17}$ En el 2001 el Parque Natural Cabo de Gata-Nijar es catalogado como Geoparque, nominación que se ratifica en 2006, entrando a formar parte de la Red de Geoparques Europeos y de la Red Mundial de Geoparques de la UNESCO.

${ }^{18}$ Las Reservas de la Biosfera son designadas por el Consejo Internacional de Coordinación del Programa MaB, a petición del Estado interesado, y quedarán sujetas a su soberanía exclusiva y a su legislación. El organismo encargado de realizar las evaluaciones preceptivas de cada Reserva de la Biosfera, valorando su adecuación o no a los objetivos y exigencias establecidas, es el Comité MaB español, adscrito al Organismo Autónomo Parques Nacionales, cuya composición, contenidos y funciones se definen en el RD 342/2007, de 9 de marzo, por el que se regula el desarrollo de las funciones del programa MaB, así como el Comité Español del citado programa $\left(\mathrm{BOE} \mathrm{n}^{\mathrm{o}}\right.$ 72, de 24.3.2007).

España cuenta actualmente con treinta y ocho reservas de biosfera nacionales y dos Reservas de la Biosfera Intercontinentales (Reserva de la Biosfera del Mediterráneo, entre Andalucía y Marruecos, y la de Gerês-Xurês, entre Galicia y Portugal), ambas incluidas en la Red Mundial del Programa MaB de la UNESCO. En cualquier caso, la declaración de un territorio como Reserva de la Biosfera no cambia en nada el sistema de planificación y gestión que exista para dicho espacio en el derecho interno de cada Estado. Entre las españolas destacamos las que ocupan espacio marino, Cabo de Gata-Nijar, la Isla de Menorca en su totalidad. Recientemente, en el 2009, ha sido declarada la Isla de Fuerteventura, que de sus 352.812 hectáreas de superficie, 187.835 se encuentran en el medio marino, constituyendo en este último aspecto la mayor extensión de mar bajo esta calificación de todo el país. Esta 'nueva' franja costera abarca hasta las cinco millas de la costa en el sector oeste y las tres millas en el resto de la isla, lo que constituye un hito en la conservación de los hábitats de la fauna y flora marinas Resolución de 30 de noviembre de 2009, de la Secretaría de Estado de Medio Rural y Agua, por la que se publica la declaración de dos nuevas reservas de biosfera españolas: Reserva de la Biosfera de Fuerteventura y Reserva de la Biosfera Transfronteriza Gerês-Xurés, entre España y Portugal (BOE, núm. 27 de 01.02.2010).

${ }^{19}$ UNESCO, Reservas de la Biosfera: La Estrategia de Sevilla y el Marco Estatutario de la Red Mundial. UNESCO, París, 1996. 
terrestre, dada la conocida confluencia de usos, y por la atención que dedica a hacerlos compatibles con el entorno; y g) Las Reservas biogenéticas del Consejo de Europa.

Junto a las figuras previstas en el artículo 49 desarrollado anteriormente, existen otros instrumentos internacionales sectoriales que generan obligaciones para España en materia de protección de la biodiversidad. La Organización Marítima Internacional (OMI) colabora en la protección de la biodiversidad marina, recurriendo a figuras como las Áreas Marinas Especialmente Sensibles y las Áreas Especiales para la Navegación (PSSAs y Sas por sus siglas en inglés), orientadas a la prevención de la contaminación del mar, en zonas que debido a su importancia ecológica, socioeconómica o científica son especialmente vulnerables al tráfico marítimo. Estas figuras surgen del Convenio internacional para prevenir la contaminación por buques de 1973, modificado por el Protocolo de 1978 (MARPOL 73/78). ${ }^{20}$

En cualquier caso, el régimen jurídico de las áreas protegidas por instrumentos internacionales será el establecido en los correspondientes convenios y acuerdos internacionales, sin perjuicio de la vigencia de regímenes de protección, ordenación y gestión específicos cuyo ámbito territorial coincida total o parcialmente con dichas áreas, siempre que se adecuen a lo previsto en dichos instrumentos internacionales, según el artículo 49.3 de la LPNB. Por su parte, la planificación y gestión de las mismas se llevará a cabo de acuerdo con las directrices de conservación que el Ministerio de Medio Ambiente, con la participación de las Comunidades autónomas deberá elaborar, siendo aprobadas mediante acuerdo de la Conferencia Sectorial de Medio Ambiente (art.49.4 LPNB). A su vez, el artículo 50 de la LPNB establece que el Ministerio de Medio Ambiente, creará por vía reglamentaria el Inventario Español de Espacios Naturales Protegidos, Red Natura 2000 y Áreas protegidas por instrumentos internacionales, que será incluido en el Inventario Español del Patrimonio Natural y de la Biodiversidad. Las CCAA deberán facilitar la información necesaria para mantener actualizado el Inventario (art. 50.3 LPNB). Todos los espacios naturales inscritos en el Inventario recibirán junto con su denominación original, la designación de las categorías establecidas internacionalmente, en especial por la Unión Internacional para la Naturaleza (UICN), a efectos de homologación (art. 50.4 LPNB). No se debe olvidar que la clasificación realizada por la UICN pretende ser un referente internacional con el fin de proporcionar una base para la comparación de las distintas legislaciones. La clasificación actual fue presentada

\footnotetext{
${ }^{20}$ El mar Mediterráneo es todo él una special area, y todas las aguas de Canarias han sido declaradas PSSAs (Particulary Sensitive Special Area) en el 2005. España forma parte, junto con Irlanda, Bélgica, Reino Unido, Francia y Portugal de la PSSA de las aguas del Atlántico Occidental declarada en 2004.
} 
en el IV Congreso Mundial de Parques Nacionales y Áreas Protegidas de 1992 y responde a VI categorías, aplicables tanto para el medio terrestre como el marino. La clasificación que realiza la IUCN aplicada al ambiente marino contempla las siguientes figuras: Reserva natural marina estricta (I); Parque nacional marino (II); Monumento natural marino (III); Área de manejo de Hábitats/Especies (IV); Paisaje protegido marino (V); y Área protegida con recursos gestionados $(\mathrm{VI})^{21}$.

En conclusión puede decirse que el derecho internacional en materia de AMPs, incide de dos maneras distintas: por un lado, hay convenios que generan la obligación a los Estados firmantes de proteger ciertos espacios situados bajo su soberanía, utilizando el Derecho interno y sometiendo las AMPs nacionales a la regulación establecida por el correspondiente Convenio o por las resoluciones de las partes contratantes en aplicación de aquel. Por otro lado, otros Convenios dan lugar a figuras especiales ad hoc, de planes de gestión de especies amenazadas, como ocurre con las zonas ACCOBAMS (Agreement on the Conservation of the Black Sea, Mediterranean Sea and contiguous Atlantic Area, por sus siglas en inglés), lo que implica que el Estado español debe proteger las especies incluidas en listas (o inventarios) y declarar espacios protegidos en los hábitats de distribución de éstas especies ${ }^{22}$. En éste último caso, España es parte tanto de ACCOBAMS para la conservación de los cetáceos en esas áreas, del Acuerdo para la Conservación de Albatros y Petreles (ACAP), y del Acuerdo sobre la Conservación de las Aves Acuáticas Migratorias de Africa y Eurasia (AEWA), todos surgidos en desarrollo de la Convención sobre Conservación de las Especies Migratorias (Convenio de Bonn, 1979).

Hasta la fecha, ni España ni ningún país europeo han propuesto ninguna zona ACCOBAMS, aunque el marco para hacerlo será en el mediterráneo el Convenio de Barcelona y su Protocolo sobre zonas especialmente protegidas y conservación de la Diversidad Biológica en el Mediterráneo, y en relación a la zona Atlántica contigua, el tratado internacional pertinente en esta materia podría ser el Anexo V sobre protección y conservación de los ecosistemas y

\footnotetext{
${ }^{21}$ RAMOS ESPLÁ, A., VALLE-PÉREZ, C., BAYLE-SEMPERE, J.T., SÁNCHEZ-LIZASO, J.L., Áreas Marinas Protegidas como herramientas de Gestión Pesquera en el Mediterráneo, Serie Informes y Estudios COPEMED, núm. 11, 2004.

${ }^{22}$ CONSEJO DE ESTADO, Informe sobre las competencias de las distintas administraciones territoriales y órganos de la administración general del estado en materia de protección de hábitats y especies marinas y de declaración y gestión de áreas marinas protegidas [evacuado con fecha 19 de julio de 2006 por la Comisión de Estudios, ejemplar mecanografiado], 2006.
} 
de la diversidad biológica de la zona marítima del Convenio OSPAR. Tampoco España ha designado hasta el momento ninguna zona ACAP, ni terrestre ni marina.

La LPNB también hace referencia en su artículo 40 a los espacios naturales protegidos transfronterizos, que se podrán constituir por áreas adyacentes, terrestres o marinas protegidas por España y otro Estado vecino. En España no se ha declarado ninguna, pero si en el mediterráneo. El Santuario Pelágico Internacional del Mar de Liguria es la primera AMP transfronteriza, que abarca tanto aguas jurisdiccionales y aguas internacionales de Francia, Italia y Mónaco, en concreto de aguas interiores y mar territorial de los tres países, así como zonas adyacentes de alta mar.

Finalmente, es preciso detenernos en la regulación de las AMPs de la Red Natura 2000. La Red Ecológica Europea Natura 2000 está integrada por los Lugares de Importancia Comunitaria (LICs) hasta su transformación en Zonas Especiales de Conservación (ZECs) y las Zonas de Especial Protección para las Aves (ZEPAS). Todos ellos tendrán la consideración de espacios protegidos Red Natura 2000 (art. 41.2 LPNB), y serán las CCAA las que establezcan las limitaciones y alcance previsto en sus legislaciones y en los instrumentos de planificación correspondientes. Ahora bien, será el Estado (a través del Ministerio correspondiente) el que elaborará con la "participación" de las CCAA, en el marco del Plan Estratégico Estatal de Patrimonio Natural y la Biodiversidad, las directrices de conservación de la Red Natura 2000, aprobadas mediante acuerdo de la Conferencia Sectorial de Medio Ambiente (art. 41.3).

La Red Natura 2000 debe incluir entre los espacios designados para formar parte de la misma, zonas marinas. Esto se manifiesta en la propia definición que la LPNB da sobre los LICs (art. 42.1), y las ZEPAS (art. 43), en las cuales se hace referencia a las aguas marinas. A pesar de esta exigencia, la superficie marina de los LICs propuestos es muy inferior a la terrestre ${ }^{23}$.

Todas las medidas de gestión de los LICs/ZECs/ZEPAS se otorgan claramente a las CCAA (art. 45.1 LPNB), sin perjuicio de que estén obligadas a remitir al Estado la información sobre las medidas de vigilancia del estado de conservación de las especies y de los hábitats, según establece el artículo 47 de la LPNB..

\footnotetext{
${ }^{23}$ Consultar tabla y cartografía realizada por el Ministerio de Medio Ambiente, Rural y Marino. Recuperado el 7 de abril de 2010 , de

http://www.mma.es/portal/secciones/biodiversidad/rednatura2000/rednatura_espana/lic/lic.htm
} 
En cuánto a las clases de AMPs que pueden formar parte de la Red Natura 2000, debemos afirmar que podrá haber AMPs marítimo-terrestres, pero también en el mar territorial, Zona Económica Exclusiva (ZEE) o incluso en aguas internacionales. Por ejemplo, aunque casi todas las ZEPAs se corresponden con espacios terrestres, hay muchas ZEPAs que pueden ser consideradas AMPs marítimo-terrestres, pues determinadas aves habitan/nidifican en acantilados, o en humedales costeros. Sin embargo muchas veces estas aves utilizan el mar como lugar reposo o especialmente, de alimentación, por lo que sería deseable designar ZEPAS incluso en aguas internacionales, o bien implementar AMPs en aguas internacionales que tengan por objeto la protección de ecosistemas importantes para las aves. En el caso de las AMPs en aguas internacionales, hasta la entrada en vigor de la LPNB no estaba claro quién las tendría que gestionar, ni quién tiene la capacidad de propuesta de inclusión de las mismas como LIC/ZEC/ZEPA marino, según el artículo 6 de la LPNB, será el Estado el competente en el caso de espacios discontinuos ecológicamente con el espacio protegido en tierra. Aunque sobre esta cuestión ahondaremos más adelante, es importante citar la Orden $\mathrm{ARM} / 3521 / 2009$, de 23 de diciembre, por la que se declaran zonas especiales de conservación los lugares de importancia comunitaria marinos y marítimo terrestres de la región Macaronésica de la Red Natura 2000 aprobados por las Decisiones 2002/11/CE de la Comisión, de 28 de diciembre de 2001 y 2008/95/CE de la Comisión, de 25 de enero de 2008 (BOE núm 315 de 31.12.2009), dictada en aplicación de la competencia de la Administración General del Estado antes señalada.

Debido a la variada y compleja tipología de figuras de espacios naturales protegidos existentes en nuestra legislación, es muy frecuente que solapen en un mismo lugar varias categorías, en estos casos las normas reguladoras de los mismos así como los mecanismos de planificación deberán ser coordinados tal y como establece el artículo 28.2 de la LPNB.

\section{Especial referencia a las Reservas Marinas de interés pesquero}

Las reservas marinas de interés pesquero son creadas por el Estado o por las CCAA, en orden a su atribución competencial sobre pesca marítima, bajo los postulados de la Ley de Pesca Marítima del Estado, la Ley 3/2001. La ley 42/2007, LPNB, no las considera expresamente AMPs, pero el Proyecto de Ley de Protección del Medio Marino (Proyecto-Ley PMM) las incluye entre los espacios naturales protegidos que formarán parte de la Red de AMPs (art. 27. e) Proyecto-Ley PMM). 
La Constitución Española a través del artículo 149.1.19 atribuye al Estado la competencia exclusiva en materia de "pesca marítima", sin perjuicio de las competencias que en la "ordenación del sector pesquero" se atribuyan a las Comunidades Autónomas. Por un lado, según diversas Sentencias del Tribunal Constitucional (57/1992, 44/2002, etc.,) la "pesca marítima”, además de la regulación de la actividad pesquera y su régimen de explotación, comprende asimismo "la normativa sobre protección y mejora de los recursos" (ciertamente, habrá que interpretar sistemáticamente el alcance de dicha función con la normativa estrictamente ambiental); por otro lado, la "ordenación del sector pesquero" integra las cuestiones relacionadas con el sector económico productivo.

Interpretado este artículo en relación al $148.1 .11^{\circ}$ (SSTC 56/1989, 147/1996 y 9/2001) el Estado dispone de dos títulos de intervención diferentes en materia pesquera: uno de carácter exclusivo, la pesca marítima, que se determinará a su vez en función de un criterio espacial, no jurídico, basado en la división entre aguas interiores, competencia exclusiva de las CCAA, y exteriores, competencia exclusiva del Estado; y otro limitado a la legislación básica (ordenación del sector pesquero). Por su parte, las CCAA que estatutariamente asumieran sus competencias en pesca marítima en aguas interiores, según Gonzalo BARRIO GARCÍA ${ }^{24}$ “ostentan plenas facultades en el dominio de su regulación”. Asimismo, las CCAA ostentan la competencia exclusiva de marisqueo y la acuicultura, manteniéndose estas actividades ajenas a la delimitación espacial de las aguas interiores/aguas exteriores (STC 103/1989). Finalmente, las CCAA ejercen las competencias de desarrollo y ejecución de la legislación básica estatal en la ordenación del sector pesquero. En definitiva, la delimitación espacial de las competencias sobre "pesca marítima" sirve para determinar qué administración pesquera puede declarar zonas de protección y conservación de los recursos pesqueros en aguas interiores o exteriores, pero no es trasladable a la conservación y uso sostenible de la diversidad biológica del medio marino, por lo tanto no resulta de aplicación para la determinación de la Administración competente en declarar AMPs como categoría específica ambiental.

En los años ochenta el Estado inició una política de legitimación y creación de las denominadas reservas pesqueras. Desde ese momento hasta la fecha, la Administración pesquera mantiene el liderazgo en la protección de la biodiversidad a través de la creación de áreas protegidas, ello debido fundamentalmente a la falta de amparo de las leyes de conservación estatales para designar áreas marinas protegidas (hasta la LPNB), y ante la

\footnotetext{
${ }^{24}$ BARRIO GARCÍA, G.A., Régimen Jurídico de la Pesca Marítima, Marcial Pons, Madrid, 1998, p. 149.
} 
urgente necesidad de preservar determinados ecosistemas o zonas para que las especies pesqueras se repoblaran. Evidentemente esta situación no deviene exclusivamente por el propio interés de la administración pesquera estatal. Es necesario recordar que la política agraria y pesquera tiene su origen en la Unión Europea (CEE, Tratado de Roma de 1957, artículos 32 a 38), y que al adherirse España a la misma cede su soberanía en esta materia a favor de las instituciones comunitarias asumiendo el "acervo común". En concreto, la pesca, entendida como gestión y conservación de recursos biológicos marinos, estaría integrada entre las llamadas competencias exclusivas de la UE, teniendo así la Comunidad plena capacidad legislativa, tanto en el orden interno como en el orden internacional.

Según el artículo 13 de la Ley 3/2001 de Pesca marítima del Estado, el órgano competente de la administración pesquera estatal podrá declarar zonas de protección pesquera para favorecer la protección y regeneración de los recursos marinos vivos, y podrán ser calificadas como: a) Reservas marinas; b) Zonas de acondicionamiento marino, c) Zonas de repoblación marina. En concreto, el artículo 14 establece que "1. Serán declaradas reservas marinas, aquellas zonas que por sus especiales características se consideren adecuadas para la regeneración de los recursos pesqueros. Las medidas de protección determinarán las limitaciones o la prohibición, en su caso, del ejercicio de la actividad pesquera, así como de cualquier otra actividad que pueda alterar su equilibrio natural. 2. En el ámbito de las reservas marinas podrán delimitarse áreas o zonas con distintos niveles de protección.”

La doctrina científica internacional agrupa en la categoría genérica de AMP a figuras tan diversas como reservas pesqueras, reservas marinas, espacios naturales protegidos marinos, etc., y la LPNB hace lo propio en relación a las dos figuras previstas en la legislación básica estatal (Reservas marinas y AMPs), ya que incluye a ambas en la Red española de AMPs. Sin embargo, que duda cabe que estamos ante dos figuras distintas que tienen conexión, en cuanto que el objeto para el cual han sido creadas está relacionado con la gestión de los recursos marinos, aunque en el caso de las reservas pesqueras se persigue hacer aumentar los recursos para su comercialización, su objetivo específico es productivista; mientras que, las AMPs, persiguen la preservación de los recursos marinos, siguiendo por tanto un objetivo específico conservacionista $^{25}$. Pero en este sentido, y en virtud del tenor literal del Anteproyecto de Ley de Pesca Sostenible (versión de 14 de octubre de 2009), se amplía a objetivos claramente ambientales la finalidad para la cual van a ser declaradas las reservas marinas, pues el artículo 14.1 del Anteproyecto establece que: "serán declaradas reservas marinas aquellas zonas que

\footnotetext{
${ }^{25}$ ORTÍZ GARCÍA, M., La gestión eficiente... cit., p. 88.
} 
por sus especiales características se consideren adecuadas para la regeneración de los recursos pesqueros, la preservación de la riqueza natural de determinadas zonas, la conservación de las diferentes especies marinas y las aves o la recuperación de ecosistemas".

Esta definición del prelegislador introduce una cierta complejidad a la delimitación de ambas categorías jurídicas, pues si ya con la actual Ley de Pesca se propicia que se declaren espacios protegidos desde una perspectiva sectorial (pesca) pero que contribuyen a través de la conservación de los recursos pesqueros, a conseguir el objetivo general de protección del medio ambiente sin que intervenga ninguna autoridad ambiental, ahora con más motivo se van a confundir terminológicamente ambas figuras pues sus finalidades se aproximan irremediablemente. Ante esta situación, sería conveniente implementar técnicas de coordinación interorgánicas y/o interadministrativa tanto en el seno de las propias Administraciones (entre los departamentos o unidades administrativas que gestionen ambos sectores) como entre Administraciones territoriales (Estado-CCAA).

\section{DISTRIBUCIÓN DE COMPETENCIAS EN EL MEDIO MARINO A LA LUZ DE}

\section{LA LEY 42/2007 DE PATRIMONIO NATURAL Y DE LA BIODIVERSIDAD}

La LPNB se ha enfrentado al reto de delimitar adecuadamente las competencias entre el Estado y las Comunidades Autónomas en relación a la biodiversidad marina. En este sentido, y siguiendo el criterio de la jurisprudencia constitucional (STC 38/2002), se admite, según Fernando LÓPEZ RAMÓN, la conservación de espacios por las Comunidades Autónomas (CCAA) en la zona marítimo-terrestre y en aguas interiores, así como "excepcionalmente" en aguas exteriores del mar territorial cuando venga exigido por la interdependencia de los ambientes marino y terrestre del espacio protegido ${ }^{26}$. Por tanto, el papel que juegan las CCAA en la gestión de los espacios marinos existentes en su ámbito territorial y aguas marinas es sumamente importante; y a su vez, dado el carácter básico de la categoría de AMP, las CCAA podrá igualmente incorporarla a su ordenamiento jurídico, junto a las categorías ya existentes en la normativa autonómica ambiental.

Según ha manifestado el Consejo de Estado en su Informe del $2006^{27}$, la conservación in situ de la biodiversidad marina con o sin AMPs, constituye una función pública que se debe llevar

\footnotetext{
${ }^{26}$ LÓPEZ RAMÓN, F., Política ecológica y pluralismo territorial. Ensayo sobre los problemas de articulación de los poderes públicos para la conservación de la biodiversidad. Marcial Pons, Madrid, 2009, p. 206.

27 CONSEJO DE ESTADO. Informe... cit.
} 
a cabo, con independencia de la Administración territorial competente para ello, con la finalidad de conservación y utilización sostenible de la diversidad biológica del medio marino. Esta postura se ha visto reflejada en la LPNB, pues el artículo 5.1 manifiesta que “todos los poderes públicos, en sus respectivos ámbitos territoriales, velarán por la conservación y utilización racional del patrimonio natural en todo el territorio nacional”, pero además extiende ésta función pública "a las aguas marítimas bajo soberanía o jurisdicción española, incluyendo la zona económica exclusiva y la plataforma continental, con independencia de su titularidad o régimen jurídico, teniendo en cuenta especialmente los hábitats amenazados y las especies silvestres en régimen de protección especial”. Asimismo, el deber de los poderes públicos manifestado en el artículo anterior es una exigencia constitucional por si misma, por un lado, la conservación de la biodiversidad marina es un componente esencial del concepto de medio ambiente del artículo 45 de la Constitución; por otro lado, gracias al artículo 96 de la $\mathrm{CE}$, los tratados internacionales válidamente celebrados por España, pasan a formar parte del Derecho interno, asumiendo España la obligación de cumplir sus compromisos internacionales derivados de diversos Convenios Internacionales que obligan a adoptar medidas para la protección de la biodiversidad marina (Convenio de Naciones Unidas sobre Derecho del Mar, Convenio de Diversidad Biológica, etc.,). La implementación en España del Derecho internacional y/o supranacional no altera el orden interno de competencias.

En relación con la creación y gestión de AMPs, la delimitación de la Administración competente ha sido un tema que ha suscitado ciertos conflictos que la LPNB ha intentado resolver. En primer lugar, se debe señalar que al no existir claramente títulos competenciales específicamente diseñados para la política de conservación in situ del medio marino, en principio se invocaron los títulos competenciales de dominio público marítimo terrestre (DPMT) y de pesca marítima como títulos habilitantes para ello. En el caso del DPMT, consolidada jurisprudencia constitucional (STCs 149/1991 y 102/1995) advierte que la condición demanial de que goza el medio marino (art.132.2 CE) no justifica un cambio en la normal distribución de competencias que haya hecho la CE y los Estatutos de Autonomía en la regulación específicamente dedicada a distribuir competencias. Por tanto, en materia de planificación y gestión de la biodiversidad marina (espacios y especies), el carácter demanial del Estado no puede invocarse como título autónomo habilitante de competencias.

En segundo lugar y en relación al título de pesca marítima, el Tribunal Constitucional (STC 38/2002) considera que "la competencia autonómica para la protección de espacios naturales 
sólo se extenderá al mar territorial cuando, excepcionalmente, así lo exijan las características del espacio protegido (...) dicha competencia se halla limitada, en el presente caso, por la competencia estatal sobre pesca marítima, que (...) resulta más específica y, por ello, ha de prevalecer en caso de colisión" (FJ 6. ${ }^{\circ}$ ). En la citada STC se delimitó claramente que las competencias ambientales de las CCAA tienen como límite las políticas sectoriales, en concreto de pesca, del Estado. En este sentido, la Ley 3/2001, de Pesca Marítima del Estado, entiende que "en las aguas exteriores de los espacios naturales protegidos, las limitaciones o prohibiciones de la actividad pesquera se fijarán por el Gobierno de conformidad con los criterios establecidos en la normativa ambiental" (art. 18.1), es decir, que en ejecución de políticas de conservación in situ de la biodiversidad marina, será el Gobierno el que establezca limitaciones a la pesca. En conclusión, la STC 38/2002 resuelve un conflicto de competencia entre pesca y medio ambiente, pero no, entre las competencias ambientales de las CCAA y las competencias ambientales del Estado.

En orden a determinar a que Administración territorial ambiental le corresponde la competencia para planificar, gestionar y declarar espacios naturales protegidos (y cualesquiera otras modalidades de áreas o lugares protegidos) no se puede utilizar evidentemente el criterio territorial asumido para la delimitación de competencias en materia pesquera. La LPNB dedica el artículo 6 exclusivamente para determinar la regla general de que la Administración General del Estado tiene la competencia en biodiversidad marina, respetando lo dispuesto en los Estatutos de Autonomía de las CCAA del litoral en los siguientes términos:

“a) Cuando se trate de espacios, hábitat o áreas críticas situados en áreas marinas bajo soberanía o jurisdicción nacional, siempre que no concurran los requisitos del artículo 36.1 .

b) Cuando afecten, bien a especies cuyos hábitats se sitúen en los espacios a que se refiere el párrafo anterior, bien a especies marinas altamente migratorias.

c) Cuando, de conformidad con el Derecho internacional, España tenga que gestionar espacios situados en los estrechos sometidos al Derecho internacional o en alta mar."

Por remisión al articulo 36.1 de la LPNB “corresponde a las Comunidades Autónomas la declaración y la determinación de la fórmula de gestión de los espacios naturales protegidos en su ámbito territorial y en las aguas marinas cuando, para estas últimas, en cada caso exista continuidad ecológica del ecosistema marino con el espacio natural terrestre objeto de protección, avalada por la mejor evidencia científica existente”. Será del Estado entonces la competencia para la protección de espacios y especies situados en áreas marinas bajo 
soberanía o jurisdicción nacional, incluidas las aguas exteriores, salvo cuando se tratara de ecosistemas que constituyeran un continuo ecológico con respecto a espacios situados en tierra o en la zona marítimo-terrestre, pues en ese caso la competencia corresponderá a las CCAA. Igualmente, la gestión de de los espacios situados en los estrechos sometidos al Derecho internacional o en alta mar será del Estado.

Comprobamos como el criterio de continuidad ecológica se convierte en un claro ejemplo de discrecionalidad técnica, habida cuenta que el propio artículo 36.1 condiciona su determinación al aval de la mejor evidencia científica existente. Serán en definitiva los técnicos, los encargados de determinar su existencia o no para así poder establecer la competencia entre el Estado y las CCAA. De cualquier modo, se trata de una excepción que habrá de ser probada por la propia Comunidad Autónoma caso por caso. En este sentido, pueden ser de gran utilidad los datos científicos que se incorporen al Inventario Nacional del Patrimonio Natural y de la Biodiversidad, con el objeto de recoger información sobre distribución, abundancia, estado de conservación y la utilización, de todos los elementos terrestres y marinos integrantes del patrimonio natural, en concreto deberá formar del mismo el Inventario Español de Habitats y Especies Marinos (art. 9.1.11 LPNB). Continúa añadiendo el artículo 36 párrafo 2 que en el caso de en que un espacio natural protegido se extienda por el "territorio" de dos o más Comunidades Autónomas, éstas establecerán de común acuerdo las fórmulas de colaboración necesarias.

En base a lo anterior, podemos extraer a su vez otra conclusión, la competencia de la Comunidad Autónoma se va a determinar por el criterio de continuidad ecológica con el territorio de la propia Comunidad Autónoma, pero no cualquier territorio, sino con el que haya sido previamente declarado como protegido, por lo que atiende a la tradicional tendencia de proteger espacios terrestres con zona adyacente marina que haría las veces de zona de amortiguamiento, y que supone la práctica habitual traducida en los espacios protegidos marítimos-terrestres. Por tanto, será el Estado el competente en las AMPs exclusivamente marinas, incluidos aquellos espacios que situados cercanos a la costa no contengan continuidad ecológica con el espacio natural terrestre de competencia autonómica. Por otro lado, el límite hacía el mar de las AMPs exclusivamente marinas puede llegar incluso a las aguas internacionales. En este sentido, el determinar el límite exterior de las AMPs marítimoterrestres con continuidad ecológica puede ser más confuso. 
Según el Consejo de Estado, ${ }^{28}$ la competencia para la planificación, declaración y gestión de ENP en aguas exteriores de las CCAA puede alcanzar aguas interiores y exteriores en la extensión misma en que los ecosistemas constituyan un continuo ecológico respecto del resto de los que están situados en tierra o en la zona marítimo-terrestre. Ahora bien, los actos de gestión de las CCAA pueden requerir la colaboración de la Administración central, al carecer aquellas de muchas de las competencias que son necesarias para gestionar AMPs (funciones de policía, etc.).

Junto a las AMPs, la LPNB también reserva al Estado las competencias relativas a los espacios naturales protegidos transfronterizos. Según Fernando LÓPEZ RAMÓN, no se reconoce la potestad de cooperación transfronteriza de las CCAA, quedando en entredicho las competencias que les atribuyen los EEAA sobre el particular (Artículo 197 EA Cataluña, 246 EA Andalucía y 98 EA Aragón) ${ }^{29}$. Se convierte así en un asunto propio del Estado en el ámbito de las relaciones internacionales, sin perjuicio, de que el Estado pueda, internamente, implementar técnicas de delegación de competencias para la mejor gestión de dichas AMPs, e incluso, de manera preceptiva en cumplimiento de regulaciones estatutarias.

Para el caso concreto de los Parques Nacionales, la Ley 5/2007, de 3 de abril, de la Red de Parques Nacionales establece que el Estado será el competente en la gestión de los Parques Nacionales situados "sobre aguas marinas bajo soberanía o jurisdicción nacional, cuando el ecosistema protegido carezca de continuidad ecológica con la parte terrestre o la zona marítimo-terrestre situadas en la Comunidad Autónoma" (art. 16.2). Pero si el parque nacional se extiende por el territorio de dos o más CCAA, éstas deberán establecer las fórmulas de colaboración necesarias para asegurar que el principio de gestión integrada se aplica correctamente. Igualmente, y tal como se ha reiterado a lo largo del presente trabajo, en el caso de que un parque nacional se sitúe en aguas exteriores, independientemente de la administración territorial competente en función del criterio de continuidad ecológica, la protección de los recursos pesqueros, así como las limitaciones o prohibiciones de la actividad pesquera, se regularán por el Gobierno, a propuesta del Ministerio de Medio Ambiente, Rural y Marino $^{30}$.

Consideramos importante la exigencia que el artículo 9 de la Ley 5/2007 impone para que un espacio pueda ser declarado Parque Nacional. Será un requisito obligatorio el que salvo casos

\footnotetext{
${ }^{28}$ CONSEJO DE ESTADO. Informe... cit., p. 330ss.

${ }^{29}$ LÓPEZ RAMÓN, F., Política ecológica y pluralismo territorial... cit., p.208.

${ }^{30}$ Artículo 17.4 de la Ley 5/2007, de 3 de abril, de la Red de Parques Nacionales.
} 
debidamente justificados, el área debe tener, al menos, 15.000 ha en Parques Nacionales terrestres o marítimo-terrestres peninsulares, 5.000 ha en Parques Nacionales terrestres o marítimo-terrestres insulares, y 20.000 ha en Parques Nacionales en aguas marinas. Hasta la fecha se han declarado dos Parques Nacionales marítimo-terrestres: el Archipiélago de Cabrera (Ley 14/1991, de 29 de abril) y las Islas Atlánticas de Galicia (Ley 15/2002, de 1 de julio).

Finalmente, y como indica Mercedes ORTIZ GARCÍA, la distribución competencial de la LPNB es extensiva a todas las figuras que amparan la protección del medio marino, es decir, LICs, ZECs, ZEPAS, ZEPIMs, etc ${ }^{31}$. Por tanto, a las CCAA les corresponde declarar y gestionar los espacios marinos que hayan adoptado alguna de las figuras de protección previstas en la Ley, siempre que se den las condición de continuidad ecológica prevista en los artículos 6 y 36.1 LPNB, siguiendo eso sí los procedimientos establecidos por la autoridad comunitaria e internacional.

\section{LA FUTURA RED DE ÁREAS MARINAS PROTEGIDAS DE ESPAÑA}

El Estado, en función de su atribución constitucional (art. 149.1.23), es el competente en dictar la legislación básica de las AMPs, y en virtud de esa potestad, la Ley 42/2007 impone que dichas áreas funcionen en estructuras de Red. El desarrollo de la Red de AMPs está previsto que se apruebe en breve a través de la futura Ley de Protección del Medio Marino, la cual viene precisamente a colmar de contenido a este y otros aspectos no previstos en la LPNB.

Los objetivos que persigue la Red de Áreas Marinas Protegidas de España van orientados a: asegurar la conservación y recuperación del patrimonio natural y la biodiversidad marina española; proteger y conservar las áreas que mejor representan el rango de distribución de las especies, hábitats y procesos ecológicos en los mares españoles; fomentar la conservación de corredores ecológicos y la gestión de aquellos elementos que resulten esenciales o revistan primordial importancia para la migración, la distribución geográfica y el intercambio genético entre poblaciones de especies de fauna y flora marinas; y a constituir la aportación del Estado español a las redes europeas y paneuropeas que en su caso se establezcan, así como a la Red Global de Áreas Marinas Protegidas ${ }^{32}$. A su vez, y según el artículo 25 del Proyecto de Ley,

\footnotetext{
${ }^{31}$ ORTÍZ GARCÍA, M., Las áreas marinas protegidas... cit., p. 443.

${ }^{32}$ Artículo 26 del Proyecto Ley de Protección del Medio Marino.
} 
“la Red de Áreas Marinas Protegidas de España está constituida por espacios protegidos situados en aguas marinas españolas, con independencia de que su declaración y gestión estén reguladas por normas internacionales, comunitarias y estatales en el medio marino, representativos del patrimonio natural marino español, así como también su marco normativo y el sistema de relaciones necesario para su funcionamiento. También quedarán integrados aquellos espacios cuya declaración y gestión estén reguladas por normas autonómicas en los supuestos establecidos en los artículos 6 y 36.1 de la Ley 42/2007 del Patrimonio Natural y la Biodiversidad". Por tanto, formarán parte de la Red, junto a los espacios marinos autonómico: a) Las Áreas Marinas Protegidas; b) Las Zonas Especiales de Conservación y las Zonas de Especial Protección para las Aves, que conforman la Red Natura 2000; c) Otras categorías de espacios naturales protegidos previstas en el artículo 29 de la Ley 42/2007 (Parques, Reservas Naturales, Monumentos naturales y Paisajes protegidos), siempre y cuando cumplan los criterios comunes y directrices de dicha Red; d) Las áreas protegidas por instrumentos internacionales, siempre y cuando cumplan los criterios comunes y directrices de dicha Red, sin perjuicio de que su declaración y gestión se ajustará a lo dispuesto en su correspondiente normativa internacional; e) La Reservas Marinas reguladas en el artículo 14 de la Ley 3/2001, de 26 de marzo, de Pesca Marítima del Estado, cuando cumplan los criterios comunes y directrices de la Red, sin perjuicio de que su declaración y gestión se realizará conforme a lo dispuesto en la Ley de Pesca.

Si interpretamos la propuesta normativa anteriormente señalada sobre el concepto de Red de Áreas Marinas Protegidas, evidentemente todo lo que esté incluido en la red será AMP, y ésta parece ser la intención del legislador tanto en la LPNB como en el Proyecto de Protección del Medio Marino como en el Anteproyecto de Ley de Pesca Sostenible, que incluye a las reservas pesqueras en la Red. Ahora bien, independientemente de la figura que se designe para la protección de los ecosistemas, comunidades o elementos biológicos o geológicos del medio marino, incluidas las áreas intermareal y submareal, el Estado ejercerá las funciones administrativas de las que es competente ajustándose a lo establecido en la Disposición Adicional Primera de la LPNB de la manera siguiente:

“a) La protección, conservación y regeneración de los recursos pesqueros en las aguas exteriores de cualquiera de los espacios naturales protegidos, se regulará por lo dispuesto en el Título I, Capítulos II y III de la Ley 3/2001, de 26 de marzo, de Pesca Marítima del Estado. b) Las limitaciones o prohibiciones de la actividad pesquera en las aguas exteriores de los espacios naturales protegidos se fijarán por el Gobierno, de conformidad con los criterios establecidos en la normativa ambiental, de acuerdo con lo dispuesto en el 
artículo 18 de la Ley 3/2001. c) Las limitaciones o prohibiciones establecidas en materia de marina mercante en espacios naturales protegidos situados en aguas marinas serán adoptadas por el Gobierno de acuerdo con lo dispuesto en la Ley 27/1992, de 24 de noviembre, de Puertos del Estado y de la Marina Mercante. d) Las funciones de la Administración General del Estado en el mar territorial, aguas interiores, zona económica y plataforma continental en materia de defensa, pesca y cultivos marinos, marina mercante, extracciones de restos, protección del patrimonio arqueológico español, investigación y explotación de recursos u otras no reguladas en esta Ley, se ejercerán en la forma y por los departamentos u Organismos que las tengan encomendadas, sin perjuicio de lo establecido en la legislación específica o en los Convenios internacionales que en su caso sean de aplicación. e) Se fomentará la coordinación entre las políticas de conservación y uso sostenible de la biodiversidad y el paisaje y los programas nacionales de investigación."

La declaración de un espacio exclusivamente marino, competencia del Estado, como AMP se llevará a cabo mediante Real Decreto, a propuesta del MARM, previo informe del Consejo Asesor de Medio Ambiente (art. 28.1 Proyecto-Ley PMM). En el caso de las AMPs autonómicas, se declararán conforme a lo previsto en la normativa correspondiente.

La gestión por su parte, siguiendo con el texto del artículo 28.2 del Proyecto de Ley, se ajustará a los criterios comunes y directrices que se dicten para la gestión coordinada y coherente de la Red. Dichas directrices, inexistentes hasta el momento, se elaborarán por el MARM y se elevarán al Consejo de Ministros para su aprobación mediante Real Decreto, previa consulta, en su caso, a la Conferencia Sectorial de Medio Ambiente. La Ley 42/2007, sin embargo deja en manos de la Conferencia Sectorial de Medio Ambiente, a propuesta de las Comunidades autónomas litorales y de la Administración General del Estado, establecer los criterios mínimos comunes de gestión aplicables a las AMPs incluidas en la Red (Art. 32.4)

El artículo 28.3 del Proyecto de Ley de PMM establece que en las Áreas Marinas Protegidas cuya declaración y gestión sea competencia autonómica en los supuestos que exista continuidad ecológica del ecosistema marino con el espacio natural terrestre objeto de protección e integradas en la Red, una vez se haya analizado caso por caso la idoneidad de su inclusión en la misma en el seno de la Conferencia Sectorial de Medio Ambiente, el Estado deberá adoptar las medidas de conservación que guarden relación con las actividades cuya regulación o ejecución sean de su competencia. Para ello, la Comunidad Autónoma encargada de la gestión podrá solicitar del MARM, bien la adopción de dichas medidas o bien, cuando 
éstas no sean de su competencia, el traslado de la solicitud al departamento oportuno (por ejemplo, defensa). En el caso de medidas de conservación que afecten a la pesca marítima, la Comunidad Autónoma deberá acreditar que ha adoptado y aplicado previamente medidas similares en las aguas interiores de dicha Área o, de lo contrario, justificar adecuadamente las razones por las que no procede adoptarlas. En cualquier caso, la gestión de las reservas marinas reguladas en el artículo 14 de la Ley 3/2001, de 26 de marzo, de Pesca Marítima del Estado, se ajustará a lo dispuesto en dicha Ley.

Una vez determinadas las competencias de la Administración General del Estado (AGE) sobre biodiversidad marina, conforme a lo previsto en la Ley 42/2007, el Proyecto de Ley de Protección del Medio Marino delimita en el artículo 29 las funciones de la AGE respecto a las AMPs exclusivamente marinas ${ }^{33}$ : “a) Gestionar las Áreas Marinas Protegidas de competencia estatal y garantizar su conservación y coordinar la Red de Áreas Marinas Protegidas de España; b) Proponer a las instituciones europeas y órganos internacionales, según corresponda, la inclusión en redes internacionales, aquellos espacios marinos de la Red de Áreas Marinas Protegidas de España que cumplan con los requisitos exigidos por sus respectivas categorías de protección; c) Declarar y gestionar las Zonas Especiales de Conservación y las Zonas de Especial Protección para las Aves en el medio marino, en los supuestos establecidos en el artículo 6 de la Ley 42/2007, de 13 de diciembre; d) Elaborar, junto con las comunidades autónomas litorales competentes en la declaración y gestión de Áreas Marinas Protegidas, la propuesta de los criterios mínimos comunes para la gestión coordinada y coherente de la Red de Áreas Marinas Protegidas de España, que aprobará la Conferencia Sectorial de Medio Ambiente; e) Realizar el seguimiento y evaluación, tanto de la Red como de sus directrices comunes; f) Fomentar y proponer instrumentos de cooperación para la consecución de los objetivos de la Red de Áreas Marinas Protegidas de España en su conjunto; g) Representar a España en las redes internacionales de Áreas Marinas Protegidas y establecer mecanismos de cooperación internacional que permitan la proyección externa de la Red; h) Aprobar y aplicar los Planes de Recuperación y Conservación de especies marinas incluidas en el Catálogo Español de Especies Amenazadas que sean de competencia estatal, según lo previsto en la Ley 42/2007, de 13 de diciembre, del Patrimonio Natural y la Biodiversidad; i) Aprobar y aplicar las Estrategias y Planes de conservación y restauración de

\footnotetext{
${ }^{33}$ Aún a riesgo de caer en demasiada transcripción literal de preceptos normativos, se justifica en la medida que se hace necesario ilustrar el Proyecto de Ley de Protección del Medio Ambiente Marino de 12 de marzo de 2010.
} 
hábitats marinos incluidos en el Catálogo Español de Hábitats en Peligro de Desaparición que sean de competencia estatal, según lo previsto en la Ley 42/2007, de 13 de diciembre.”

\section{VALORACIÓN FINAL SOBRE LAS COMPETENCIAS AUTONÓMICAS EN EL MEDIO MARINO}

La incorporación de AMPs al ordenamiento jurídico ambiental español, supone un gran acierto, acrecentado si cabe por la exigencia de conectarlas en estructuras de red que permita, a modo de corredores, proteger grandes superficies de medio marino.

Este objetivo se corresponde con el deber de los poderes públicos de velar por la conservación y utilización racional del patrimonio natural en todo el territorio nacional y como se reitera a lo largo de la LPNB, en las aguas marinas de soberanía o jurisdicción española. En este sentido, la LPNB pone de manifiesto en su articulado el esfuerzo realizado por el legislador para delimitar adecuadamente las competencias entre las distintas Administraciones territoriales implicadas en la conservación de la biodiversidad marina, no sin cierta complejidad.

Como se ha señalado, las competencias de las CCAA sobre biodiversidad marina, según lo previsto en el artículo 6 y 36.1 de la LPNB, se darán en el caso de las AMPs marítimoterrestres o con continuidad ecológica en aguas interiores o incluso exteriores. Por su parte, el Estado será el competente en las AMPs strictu sensu, es decir, las que acojan exclusivamente el medio marino ${ }^{34}$, respetando lo dispuesto en los Estatutos de Autonomía de las CCAA con litoral (art. 6 LPNB). En este sentido se puede concluir que la competencia del Estado es la regla general y la excepción es la de las CCAA, pero determinados EEAA contienen especialidades que han permitido declarar y gestionar espacios naturales protegidos en el mar.

Precisamente, la reserva que algunos EEAA (como es el caso de Murcia) ${ }^{35}$ otorgan a la Comunidad Autónoma respectiva para extender su competencia exclusiva a la protección de

\footnotetext{
${ }^{34}$ ORTÍZ GARCÍA, M., "Las áreas marinas protegidas y la ordenación sostenible e integrada del litoral”, Sanz Larruga, J. (dir), García Pérez, M. (coord.), Estudios sobre la ordenación, planificación y gestión del litoral: Hacia un modelo integrado y sostenible, Instituto de Estudios Economicos de Galicia Pedro Barrié de la Maza Observatorio del Litoral de la Universidad de A Coruña, A Coruña, 2009, p. 433.

${ }^{35}$ El Estatuto de Autonomía de la Región de Murcia, desde su redacción original (LO 4/1982, de 9 de junio), reserva a la Comunidad Autónoma la competencia exclusiva de pesca en aguas interiores, marisqueo, acuicultura y alguicultura, así como el desarrollo de cualquier otra forma de cultivo industrial. Caza y pesca fluvial, y la protección de los ecosistemas en los que se desarrollan dichas actividades (art. 10.9 LO 1/1998, de 15 de junio, de Reforma del Estatuto de Autonomía de la Región de Murcia). A su vez, ostenta la competencia para el desarrollo legislativo y la ejecución en materia de espacios naturales protegidos (art. 11.2 LO 1/1998, de 15 de junio).
} 
los ecosistemas situados en aguas interiores, obliga a preguntarnos si en base al Estatuto de Autonomía podrían declararse y gestionarse AMPs en espacios marinos cercanos a la costa sin continuidad ecológica con el espacios terrestre protegido, fórmula como sabemos reservada al Estado por la legislación básica.

En este sentido, existe una clara doctrina del TC (ss. TC 37/1981, fj. núm. 1, y 5/1982, fj. núm. 1), que como apunta Antonio GUTIÉRREZ LLAMAS, puso en cuestión la pretensión de exclusividad competencial contenida en los EEAA, calificando de exceso semántico la calificación como "exclusivas" de competencias que son "compartidas" por imperativo de la $\mathrm{CE}^{36}$. Continúa el autor afirmando que "atendiendo a la jurisprudencia constitucional, las denominadas competencias exclusivas han de enmarcarse en el bloque de la constitucionalidad e interpretarse sistemáticamente los preceptos correspondientes de la Constitución y de los Estatutos de Autonomía”. Por tanto, el que alguna Comunidad Autónoma haya asumido la protección de los ecosistemas en los que se desarrollan determinadas actividades (pesca, marisqueo, acuicultura, etc.), debe interpretarse sistemáticamente con el título competencial de desarrollo legislativo y la ejecución en materia de espacios naturales protegidos, que no es una competencia exclusiva y debe enmarcarse necesariamente en la legislación básica estatal. En caso contrario, de intentar una interpretación como título competencial exclusivo la protección de los ecosistemas en los que se desarrollan dichas actividades, estaríamos ante una extralimitación competencial, que debe reducirse mediante su encaje con la competencia estatal ex. art. 149.1.23a . Por su parte, el Consejo de Estado afirma que "en el caso de que un Estatuto de Autonomía atribuya a una Comunidad Autónoma competencias de gestión de la biodiversidad marina o de espacios naturales protegidos en aguas interiores o en el mar territorial, dichas competencias, especialmente en el segundo supuesto, si se ejercen en espacios discontinuos con el territorio autonómico terrestre o marítimo-terrestre, serían de ejercicio necesariamente conjunto con las competencias estatales sobre el mar territorial" ${ }^{\text {37 }}$.

Otra cuestión que puede crear confusión es la relativa a las competencias sectoriales de las CCAA del litoral español, nos referimos a las que se ejercen principalmente en materia de pesca en aguas interiores, sobre la base de los apartados 13 y 19 del artículo 149.1 y el art 148.1.11 de la CE. El TC ha delimitado a través de diversos pronunciamientos (STCs

\footnotetext{
${ }^{36}$ GUTIERREZ LLAMAS, A., 2008. "Las competencias autonómicas: Evolución del sistema competencial de la Región de Murcia”, López Pellicer, J.A., Gálvez Muñoz, L.A. (coords.), Derecho Autonómico de la Región de Murcia, Universidad de Murcia, Servicio de Publicaciones, Murcia, p. 140.

${ }^{37}$ CONSEJO DE ESTADO, Informe ... cit., p. 333.
} 
56/1989, 147/1991, 185/1996, o 9/2001) los títulos competenciales de pesca marítima y ordenación pesquera determinando que la distribución de funciones a nivel estatal y autonómico se funda en criterios distintos. Así, en el caso de pesca marítima, se aplica un criterio territorial por el cual la pesca en aguas interiores corresponde a las CCAA, mientras que la pesca en aguas exteriores sería competencia estatal; en el caso de la ordenación del sector pesquero, siguiendo el binomio bases-desarrollo, las CCAA ejercen sus competencias normativas y ejecutivas de ordenación del sector pesquero en el marco de la legislación básica del Estado.

A la interrelación existente entre las figuras de protección del medio marino creadas tanto por la administración ambiental como la pesquera (AMP y Reservas Marinas respectivamente), en relación con los resultados comunes que pueden llegar a alcanzar en aras de la protección del medio ambiente (ya analizados en páginas anteriores), se suma la necesaria coordinación interorgánica y/o interadministrativa que debe ser objeto de un gran empeño entre estas Administraciones implicadas. Para ello, y en virtud de la ya consolidada teoría de gestión basada en el ecosistema, por un lado, y de la pesca sostenible, por otro, consideramos y compartimos la opinión del Consejo Ecónomico y Social de la Región de Murcia (CESRM) ${ }^{38}$, en relación a que la regulación de la Consejería con competencias en materia de pesca en las zonas de los espacios dotados de un régimen especial de protección ambiental no debe limitarse a tomar en consideración los criterios establecidos en la normativa ambiental específica de estas zonas sino que debe respetar e integrar ${ }^{39}$ dicha normativa en la regulación de las actividades pesqueras, incluyendo por tanto las condiciones y requisitos que dicha normativa ambiental pueda haber establecido y que tengan relación con las citadas actividades pesqueras.

\section{BIBLIOGRAFÍA}

BARREIRA, A., et al., Gobernanza para la protección del medio marino en España: Guía Práctica, Madrid, Instituto Internacional de Derecho y Medio Ambiente (IIDMA), 2009.

BARRIO GARCÍA, G.A., Régimen Jurídico de la Pesca Maritima, Marcial Pons, Madrid, 1998.

\footnotetext{
${ }^{38}$ Dictamen 1/2006, sobre el Anteproyecto de Ley 2/2007, de 12 de marzo, de Pesca Marítima y Acuicultura de la Región de Murcia.

${ }^{39}$ La cursiva es del autor.
} 
CONSEJO DE ESTADO., Informe sobre las competencias de las distintas administraciones territoriales y órganos de la administración general del estado en materia de protección de hábitats y especies marinas y de declaración y gestión de áreas marinas protegidas [evacuado con fecha 19 de julio de 2006 por la Comisión de Estudios, ejemplar mecanografiado], 2006.

GUTIERREZ LLAMAS, A., "Las competencias autonómicas: Evolución del sistema competencial de la Región de Murcia”, López Pellicer, J.A., y Gálvez Muñoz, L.A. (coords.), Derecho Autonómico de la Región de Murcia, Universidad de Murcia, Servicio de Publicaciones, Murcia, 2008.

KELLEHER, G., Guidelines for Marine Protected Areas, IUCN, Gland - Cambridge, 1999.

LÓPEZ RAMÓN, F., Política ecológica y pluralismo territorial. Ensayo sobre los problemas de articulación de los poderes públicos para la conservación de la biodiversidad, Marcial Pons, Madrid, 2009.

ORTÍZ GARCÍA, M., La gestión eficiente de la zona costera. Los Parques marinos. Tirant lo blanch, Valencia, 2003.

— "La conservación de la biodiversidad marina: las áreas marinas protegidas", Comares, Granada, 2002.

— "Las áreas marinas protegidas y la ordenación sostenible e integrada del litoral", Sanz Larruga, J. (dir), García Pérez, M. (coord.), Estudios sobre la ordenación, planificación y gestión del litoral: Hacia un modelo integrado y sostenible, Instituto de Estudios Economicos de Galicia Pedro Barrié de la Maza - Observatorio del Litoral de la Universidad de A Coruña, A Coruña, 2009.

RAMOS ESPLÁ, A., VALLE-PÉREZ, C., BAYLE-SEMPERE, J.T. y SÁNCHEZ-LIZASO, J.L., Áreas Marinas Protegidas como herramientas de Gestión Pesquera en el Mediterráneo, Serie Informes y Estudios COPEMED, núm. 11, 2004.

UICN, Directrices para las categorías de Manejo de Áreas protegidas, Centro de Parques Nacionales y Áreas Protegidas (CPNAP) - Centro Mundial de Monitoreo de la Conservación (WCMC), Cambridge, 1995.

UNESCO, Reservas de Biosfera: La Estrategia de Sevilla y el Marco Estatuario de la Red Mundial, UNESCO, París, 1996. 
WWF. (2005, septiembre) Conservando nuestros paraisos marinos. Propuesta de Red Representativa de Áreas Marinas Protegidas de España. Recuperado el 7 de abril de 2010 de http://assets.wwfes.panda.org/downloads/conservando nuestros paraisos marinos penins ula_iberica_y_baleares1.pdf 